\title{
Getting back to basics: risk fundamentals applied to the geotechnical engineering of tailings storage facilities
}

\author{
JP Coffey Rio Tinto Iron Ore, Australia \\ N Susic Rio Tinto Iron Ore, Australia
}

\begin{abstract}
Inherent uncertainty associated with the selection of input parameters to various geotechnical analyses often results in the likelihood of failure being a dominant topic in the discussion of risk associated with geotechnical assets. As a result, embankment failure is the default risk scenario driving ongoing management of tailings storage facilities (TSFs). This commonly applied approach is inefficient as it drives resource intensive TSF management and limits scope for a risk-based approach. However, many TSFs operate with several layers of controls in place. Therefore, assessment of risk with consideration of these controls would promote greater efficiency in TSF management.

A fit for purpose approach will be discussed that demonstrates how risk can be utilised as the foundation for the development of a management framework for a single or portfolio of TSFs. This approach focuses on the identification and monitoring of controls, based on the understanding that hazards impact when the controls put in place to manage them fail. It is necessary to build such an approach with the full application of risk principles, which will be introduced by a specialist in corporate risk. Topics covered include a brief history of risk, importance of control effectiveness in scenario selection and risk evaluation and communicating value at risk to drive resource allocation. It is hoped that this discussion and presentation of simple examples allows risk concepts to be better applied to the design and management of geotechnical structures.
\end{abstract}

Keywords: tailings storage facility, risk, Probability of Failure, controls

\section{Introduction}

\subsection{Risk basics}

Dealing with risk effectively is a source of sustainable competitive advantage (PricewaterhouseCoopers 2012). This is not surprising given its definition as 'the effect of uncertainty on objectives' (International Organization for Standardization 2018). Consequently, effective management of risk is likely to improve stakeholder confidence in the entity's ability to meet its strategic and operational objectives.

A number of elements supporting today's use of risk management evolved over time but it was Blaise Pascale's contribution in the 1600s that provided the framework for understanding risk today: "...So, then, our fear of some harm ought to be proportional not only to the magnitude of the harm, but also the probability of the event" (Arnauld \& Nicole 1996). In other words, risk = likelihood $\times$ consequence (e.g. Sotic \& Rajic 2015). As organisational objectives are forward looking, risk too relates to future events and their consequences (Aven \& Renn 2009). As most organisations face risk in their operational activities, the main purpose of risk management is to enable understanding of the uncertainties and manage their impact on organisational objectives such that value is either protected or maximised. This is achieved by analysing the risks that matter and appropriately assigning resources to the management of those risks that exceed the organisation's acceptance threshold.

Organisational objectives can have different aspects (economic, non-economic or both) and can apply at different levels. Consequently, risk needs to be managed across different areas of the organisation, and the three lines of defence (3LOD) model is commonly used to achieve this. Broadly, it suggests that the first line 
of defence is the risk owners who are responsible for owning and managing risk. The second line is the risk function and their role is to ensure the integrity of the risk management process. The third line of defence is the internal audit (Institute of Internal Auditors 2013).

The responsibility for management of risks is delegated to the first line as it encompasses personnel with technical skills, operational understanding and the organisational mandate to manage risk. They achieve this through controls or the means an organisation has in place to modify the inherent risks associated with the operational activities.

\subsection{Risk assessment applied to tailings storage facilities}

The inherent risk in the context of tailings storage management is a catastrophic failure of the embankment. A tailings management control framework will contain measures at key stages in a tailings facility lifecycle (planning, design, construction, operation and closure) to ensure that the likelihood of the failure is reduced below the organisational risk acceptance threshold and/or regulatory guidelines (e.g. Australian National Committee on Large Dams (ANCOLD) 2012; Mining Association of Canada (MAC) 2017). Failure to design the controls appropriately and assure their effective implementation across lines one and two will result in a greater likelihood of the inherent consequence manifesting. Indeed, risks impact because controls fail.

As with most organisational processes, tailings management controls such as geotechnical investigations, construction supervision or deposition management have a strong human element. Martin and Davies (2002) state that stewardship is of equal significance to technical design because under proper stewardship design, errors can be detected and, in some instances, prevented from manifesting themselves as failures. In this paper it is proposed that a risk-informed basis is used as the starting point for the determination of the management structure and processes for one or multiple tailings storage facilities (TSFs). However, the definition of the risk posed by a TSF at different stages of its life is not simple, and a consolidated approach that links management decisions and TSF performance is not common in the literature.

From a geomechanics perspective, risk assessment of TSFs often focus on the quantification of likelihood of a hazard impacting. Conversely, common industry guidance such as the International Committee on Large Dams, Australian National Committee on Large Dams, Dams Safety Committee of New South Wales and Department of Mining, Industry Regulation and Safety (Western Australia) focus on the inherent consequence of failure to categorise a TSF (i.e. no consideration is given to the presence or effect of controls), which is in most cases a conservative position. In order for an owner to manage multiple TSFs, the two approaches need to be combined. An initial assessment of the likelihood and consequence can be followed by a second assessment considering current or proposed risk controls that may reduce the credible likelihood and consequence. These risk controls enable the risk-based management structure for the TSF, in addition to external requirements for legal compliance and insurance.

Quantification of the likelihood of failure is often a time-consuming and subjective process. If the approach adopted by the US Department of the Interior Bureau of Reclamation is considered, the likelihood of failure is made up of two components: the probability of a given load or scenario occurring and the Probability of Failure (PF) should that load or scenario occur (US Department of the Interior Bureau of Reclamation 2015). On face value, the first component may be relatively simple for natural events, magnitudes of which are often determined through a probabilistic analysis, such as rainfall and ground motions arising from seismic events. However, failure of a TSF is not always the result of natural events. Take for example the determination of the probability that a TSF overtops through poor management of the supernatant pond. This is a highly subjective assessment, which is made more difficult without understanding the controls that are in place. Determination of the PF of a TSF given the load or scenario under examination occurring is also often subjective, to varying degrees, as it requires some engineering judgement. This position has been reported by several authors, among them:

"...however good the mathematics look, assessment of risk is heavily founded in judgement." (Murray et al. 2010) 
"Failure Mode and Effects Analysis (FMEA), and most other qualitative risk assessment methods, are nothing more than organized judgement, common sense with a fancy name." (Martin \& Davies 2002)

An alternative approach to the definition of the likelihood of failure is presented by Oboni and Oboni (2016), in which human performance at the various life stages (planning, design, construction, operation and closure) of a TSF are considered in determining the likelihood of failure. This is a logical approach as the majority, if not all, controls that could be employed to reduce the risk posed by a TSF include a human element. This method, although appropriate, is undoubtedly subjective. Consequently, although quantification of the likelihood of failure is a powerful tool, especially in the determination of risk controls, it may be overly complex as the basis for ongoing management decisions for a TSF.

Regulatory and industry guides focus on the inherent consequence (i.e. catastrophic failure of a TSF) as the default scenario for consequence assessments. This approach is valid, as it is used to determine the minimum controls that should be employed. However, this is problematic for a risk-based TSF management approach as it fails to recognise that an effective suite of controls can alter the credible consequence for a period of time. For example, an effective set of controls may suggest that the likelihood of an embankment failure is quite low but that a lesser scenario such as an embankment instability requiring urgent remediation may be more likely. The deterministic nature of such a conservative approach is not only resource intensive but also likely exacerbated for a portfolio of TSFs.

The source of this difficulty is a misalignment between the current likelihood of failure and the inherent consequence. It is reasonable to assume that several controls are likely to be present, such as minimum design criteria, and operational requirements such as minimum freeboard. On top of mandatory requirements, mine owners and operators commonly have their own policies dictating further controls.

Alignment of current likelihood and consequence of failure may create an environment in which eroding control effectiveness is more visible leading to a potential change in the likelihood of an inherent scenario. When this is the case, the required action is very clear: restore control effectiveness and return the TSF-related uncertainty to within the acceptable threshold.

The alignment of the assessment of likelihood and consequence also allows more effective communication, which aids effective management of a TSF. Several authors (Boshoff et al. 2015; Murray et al. 2010; Bruce \& Oboni 2002) suggest that a suitably knowledgeable and well-informed management team is a necessary component for successful TSF management. For example, if it has been determined that catastrophic failure without significant warning is not credible for a given TSF while all controls are effective. However, if the operational performance worsens and several controls become ineffective, it may consequently be shown that a catastrophic failure and rapid impact to the inundation zone downstream is credible.

However, it may be possible that the manager responsible for the TSF does not have a robust understanding of the technical aspects of a TSF, so communicating any changes in the risk level relative to the business objectives is more likely to result in action than a technical communique indicating a change in likelihood alone. Better still, if the critical controls for TSF failure have been designed to minimise the likelihood of a catastrophic failure, the communication to the responsible manager should also inherently include the actions required to reduce the risk profile to align with the design case, as discussed above. This point is important as the failure to take reasonable precautions and exercise due diligence to prevent the commission of failure may lead to legal implications for the organisations (Payne v TIWEST Pty Ltd 2005).

Finally, the various industry guides often do not clearly define the business importance of a TSF. This is understandable and highlights the need for an owner to have well defined risk assessment and management procedures. One exception is mentioned in the Mining Association of Canada's (MAC) 2017 guide where it is highlighted that the owner's business risk may exceed what is assessed if the only controls are those suggested within industry standards and/or regulations (MAC 2017). 
This discussion mentions risk controls several times. This is a key component of the most recent MAC guide (MAC 2017). In this guide, a critical control is defined as:

"... a risk control and associated performance measures that defines actions designed to assist the management of high-consequence risks relating to a tailings facility. Critical controls may be technical, operational or governance in nature. Critical control management is a governance approach to managing high-consequence risks relating to an operation or business"

Further, critical controls are implemented effectively to either prevent a serious incident occurring, or to limit the consequences if a serious incident were to occur (MAC 2017). Continual monitoring of controls is complimentary to other ongoing management techniques, such as the observational approach advocated by ANCOLD (2012). In this instance, when an unexpected condition is experienced, one must ask themselves if it is a failure of a control or if a change has occurred (which ideally would have been identified and managed) and one or more controls may need to be modified to facilitate ongoing successful management.

\section{Example case}

The following example considers a hypothetical mine site with a single TSF, which is an upstream raised TSF with a maximum height of $30 \mathrm{~m}$ and 1 (vertical) to 4 (horizontal) slopes. The TSF has been designed to comply with the deterministic limits recommended in Australian National Committee on Large Dams (ANCOLD) (i.e. a long-term, drained Factor of Safety (FS) greater than 1.5).

The TSF has four operational controls that have been defined and are incorporated within the facility's Operating Maintenance and Monitoring (OMM) manual:

1. Operations must maintain a $100 \mathrm{~m}$ dry beach.

2. An underdrain immediately upstream of the starter dyke.

3. Daily inspections.

4. Monthly monitoring of pore pressures and embankment displacements.

A cross-section of the impounding embankment is presented in Figure 1. The material properties applied in the deterministic stability analysis are presented in Table 1 and the additional details on the probability distribution function (PDF) characteristics are presented in Table 2. Note that all PDFs are assumed to be normally distributed, with the minimum and maximum shear strengths capped at three standard deviations from the mean. This approach is presented in Dai and Wang (1992) and Duncan (2000).

Table 1 Original deterministic material properties adopted in example case

\begin{tabular}{|c|c|c|c|c|c|c|c|c|}
\hline $\begin{array}{l}\text { Material } \\
\text { name }\end{array}$ & Colour & $\begin{array}{l}\text { Unit } \\
\text { weight } \\
\left(\mathrm{kN} / \mathrm{m}^{3}\right)\end{array}$ & Strength type & $\begin{array}{l}\text { Cohesion } \\
\text { (kPa) }\end{array}$ & $\begin{array}{l}\text { Phi } \\
\text { (deg.) }\end{array}$ & $\begin{array}{l}\text { Vertical } \\
\text { stress } \\
\text { ratio }\end{array}$ & $\begin{array}{l}\text { Minimum } \\
\text { shear } \\
\text { strength } \\
(\mathrm{kPa})\end{array}$ & $\mathrm{Ks}(\mathrm{m} / \mathrm{s})$ \\
\hline Earthfill & & 22 & Mohr-Coulomb & 0 & 34 & & & $1.00 \mathrm{E}-06$ \\
\hline Tailings & & 18 & $\begin{array}{l}\text { Vertical stress } \\
\text { ratio }\end{array}$ & & & 0.3 & 10 & $1.00 \mathrm{E}-07$ \\
\hline Foundation & & 18 & Mohr-Coloumb & 5 & 28 & & & $1.00 \mathrm{E}-09$ \\
\hline Drain & & 20 & Mohr-Coloumb & 0 & 34 & & & $1.00 \mathrm{E}-04$ \\
\hline
\end{tabular}


Table 2 Original probabilistic material properties for example case

\begin{tabular}{llllll}
\hline & Material name & Property & Distribution & Mean & Std. dev. \\
\hline 1 & Earthfill & Phi & Normal & 34 & 4 \\
2 & Tailings & Vertical stress ratio & Normal & 0.3 & 0.1 \\
\hline
\end{tabular}

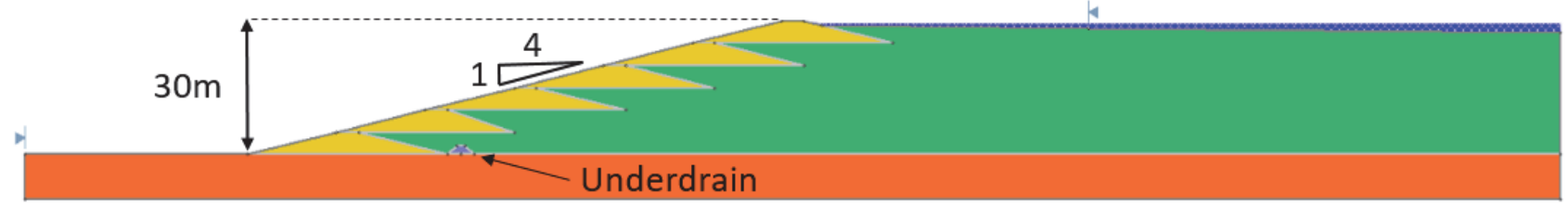

Figure 1 Geometry of example TSF with no dry beach

The following discussion focuses on a series of events that occur on the site. Two different responses are presented; one focusing on a detailed determination of the likelihood of failure to inform management decisions and another that focuses on control management. A summary of the results is presented in Table 3 .

Table 3 Results of analysis completed at different stages within the example case

\begin{tabular}{|c|c|c|c|c|c|c|}
\hline Step & $\begin{array}{l}\text { Beach } \\
\text { width }(\mathrm{m})\end{array}$ & $\begin{array}{l}\text { Underdrain } \\
\text { status }\end{array}$ & $\begin{array}{l}\text { Strength } \\
\text { data }\end{array}$ & FS & $\begin{array}{l}\text { PF } \\
\text { (\%) }\end{array}$ & Comments \\
\hline 1 & 100 & Operating & Original & 1.52 & 12 & Per design, judged to be acceptable \\
\hline 2 & 60 & Operating & Original & 1.45 & 18 & $\begin{array}{l}\mathrm{FS}<1.5 \text {, so complete more geotechnical } \\
\text { investigation and testing to justify an } \\
\text { increase in strength parameters }\end{array}$ \\
\hline 3 & 60 & Operating & Updated & 1.44 & 9 & $\begin{array}{l}\text { Fill strength increased, standard } \\
\text { deviation of tailings undrained shear } \\
\text { strength reduced, PF reduced to a low } \\
\text { value }\end{array}$ \\
\hline 4 & 30 & Operating & Updated & 1.36 & 10 & $\begin{array}{l}\text { Plant operating with low solids due to } \\
\text { poor feed reduces beach. FS is low but } \\
\text { PF is same as design so scenario } \\
\text { accepted, but needs to be addressed } \\
\text { next year }\end{array}$ \\
\hline 5 & 30 & Clogged & Updated & 1.30 & 15 & $\begin{array}{l}\text { Wet spots observed near downstream } \\
\text { toe, appears underdrain is now clogged. } \\
\text { PF too high, need to action and } \\
\text { exposure to continuing poor operation } \\
\text { or a storm is now high (see step 6) }\end{array}$ \\
\hline 6 & 0 & Clogged & Updated & 0.94 & 57 & $\begin{array}{l}\text { Scenario modelled to define risk of } \\
\text { storm event or continuing poor } \\
\text { operations }\end{array}$ \\
\hline
\end{tabular}

The discussion of the consequence of failure is not included in this example, as it is considered equal for each scenario for both approaches. However, definition of the consequence of the worst credible failure associated with each scenario discussed would be necessary in reality, in order to consider the TSF in the context of the owner's other assets and risk tolerance. 


\subsection{Step 1}

Figure 2 presents the results of the stability analysis for the design case (long-term drained shear strengths), with control 1 successfully implemented (i.e. a $100 \mathrm{~m}$ dry beach), which is confirmed through successful implementation of control 3 (daily inspections). As can be seen, the desired FS for compliance with ANCOLD recommendations has been achieved. The Probability of Failure (PF) has been estimated as $12 \%$ through Monte Carlo analysis, based on the inputs stated in Table 2. The underdrain (control 2) is functional at this point in time, and is effectively controlling the phreatic below target levels for the phreatic surface (confirmed via control 4).

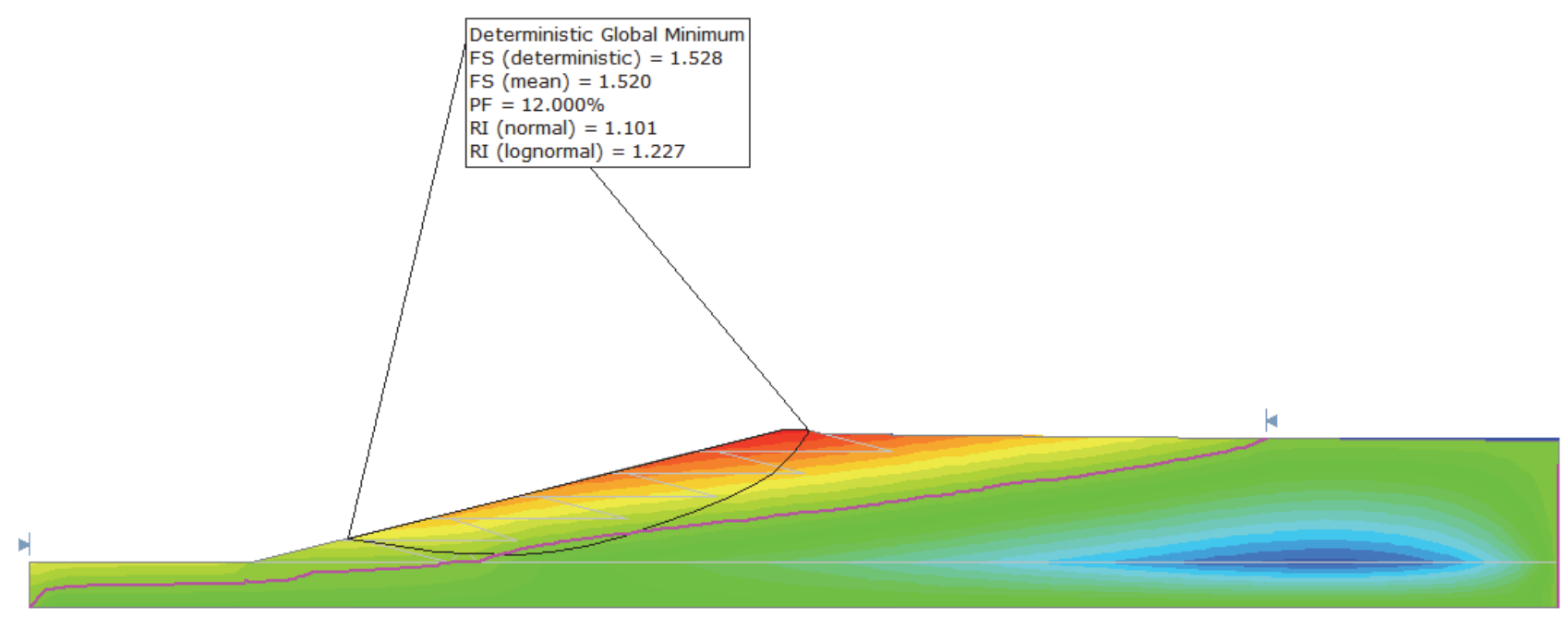

Figure 2 Design stability analysis results for the design case

\section{$2.2 \quad$ Step 2}

After a period of time, control 4 (monitoring) identifies that the phreatic surface has exceeded its trigger level. Upon review it is clear that control 3 (inspections) have been ineffective for the past few months, which has meant that control 1 (a $100 \mathrm{~m}$ dry beach) is no longer in place, with the width of the dry beach having reduced to $60 \mathrm{~m}$.

As three controls have been identified as being ineffective, the site's engineering consultant is asked to complete stability analysis of the scenario. This results in an FS of 1.45 and a PF of $18 \%$ (replicated in Table 3).

\subsection{Step 3}

As the FS is now below the desired value and the PF is now higher than the design case, some action is requested by the site's management. The site's engineering consultant points out that the breadth of the PDFs for material inputs in the stability analysis could be reduced through additional geotechnical investigation, as the original analysis was quite conservative. This concept is often described using the coefficient of variance (COV), which is the ratio of the standard deviation and the mean. Thus, an equal PF may occur for a high and low FS, if the COV is changed proportionately (Christian et al. 1994; Duncan 2000). Subsequently, additional examination of the previous test results is undertaken and the internal angle of friction of the earthfill in the deterministic analysis is increased to 36 degrees (i.e. Table 1 is updated) and the standard deviation of the shear strength of the tailings is reduced to 0.07 in the probabilistic analysis (i.e. Table 2 is updated). Subsequent analysis with these inputs shows that the FS shows a minor reduction to 1.44 , but the PF is reduced significantly, to $9 \%$, which is below the design case, and so continued operation with a $60 \mathrm{~m}$ beach is accepted. 


\section{$2.4 \quad$ Step 4}

After a year of processing low-grade ore, the dry beach has reduced to only $30 \mathrm{~m}$. This situation is accepted on the basis that it is only for a short period of time as higher grades are forecast for next year, controls 3 (daily inspections) and 4 (monitoring) have been successfully implemented, the TSF has successfully been operated with a reduced beach width previously, and updated stability analysis shows that the FS reduces to 1.36 and the PF is increased to $10 \%$ (Table 3).

\subsection{Step 5}

Soon in the new year, the daily inspections (control 3 ) identify that wet spots have developed near the downstream toe of the embankment. This finding is supported by review of the monitoring results of the in situ pore pressures (control 4). The site's engineering consultant inspects the issue and advises that the underdrain has likely become clogged and can no longer effectively draw down the phreatic surface within the embankment. A subsequent stability analysis is undertaken, which shows the FS is reduced to 1.30 (Table 3). These results concern management greatly, as the FS is now only just above any acceptable limit in ANCOLD (2012) (even for a short-term undrained case with no potential loss of containment) and the PF, at $15 \%$, is higher than at any stage previously.

\subsection{Step 6}

The unease with the current operating condition prompts a risk review of the facility. During this review, it is identified that with only a $30 \mathrm{~m}$ dry beach, the facilities water storage capacity has been significantly reduced. As such, the site's engineering consultant is asked to analyse the impact on stability of a situation with no dry beach. The results show an unacceptably low FS at 0.94 , with a PF of $57 \%$ as shown in Figure 3.

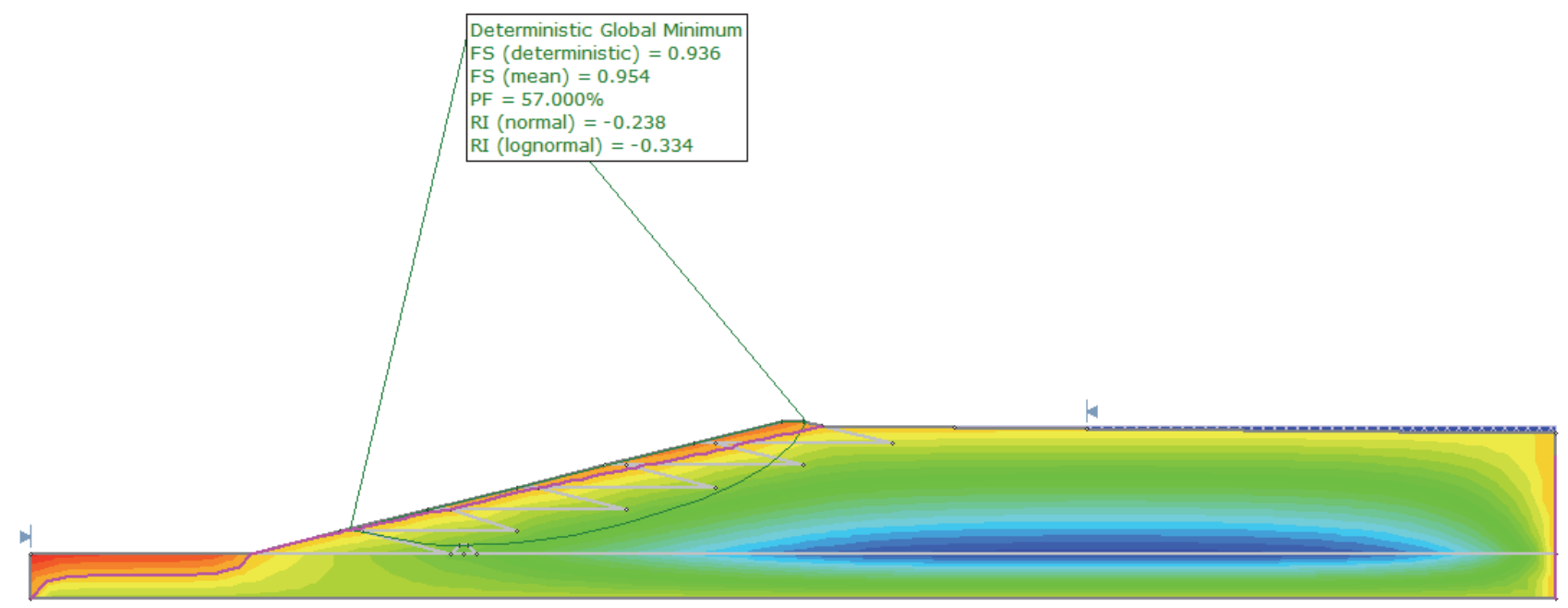

Figure 3 Results of stability analysis with no dry beach and an inoperable underdrain

The site's management is now faced with a very difficult decision. Both physical controls (1 and 2) are ineffective and the facility has been shown to be significantly exposed to a storm event. There are two options: shut down the process plant for a period of time and/or install additional decant infrastructure to draw down the pond.

\section{Discussion}

From an enterprise risk management perspective, the example provided starts with a clearly articulated operational control management framework. Four controls appear to be interconnected and as they have been deemed as critical, one can assume that the performance criteria for each has been developed. 
As the operations continued, it became obvious that the control performance criteria have not been adhered to, which lead to the unobserved reduction in the width of dry beach to $60 \mathrm{~m}$. This deviation from the agreed protocols should have triggered an investigation to understand the root causes of the non-compliance with critical control requirements. In addition, a parallel instruction to increase the number of inspections of the facility until the desired width of the beach head is restored could have been made. This change would have assisted to reduce the likelihood of failure while operating outside the established controls.

Quantitative analysis of the current state by the consultant wouldn't have directly contributed to the restoration of the critical controls and its value should have been questioned. Although this can be acceptable if change management procedures are effectively implemented, in the example there was never actually a physical response to one of the controls becoming ineffective. For example, in step 3, additional geotechnical investigation and testing is undertaken. The results actually show that the original design did not meet its objective (i.e. FS $>1.5$ ), which should have triggered physical modifications to the embankment. Continuing to operate with the original set of controls did not serve to meet the tolerable risk threshold, as they had been derived by the original analysis and subsequently shown to be inadequate in combination with the updated analysis in step 2.

Somewhat alarmingly, it would appear that the quantitative analysis provided the operational team with a false sense of security despite the fact that there was a blatant deviation from the critical controls. Management should have recognised that loss of control effectiveness is a leading indicator of failure and steps should have been taken despite potential favourable operational conditions to restore the critical controls and regain control of the tailings facility. This is especially true for the state reached in step 4, where maintaining production (i.e. revenue) was prioritised over management of the TSF. Alternate responses could have been to look for additional operational controls or capital expenditure to modify the TSF to achieve an acceptable state.

By the time we get to step 6, the analysis has concluded what is already known: the reduced dry width of the beach has created undesirable phreatic conditions that may manifest as unexpected economic implications for the operation associated with arresting the production of tailings. What is more, management appear to be left with limited room to manoeuvre as the remedial actions are now a matter of priority. Resources aimed at mitigating risks in other parts of the organisation now need to be redirected to manage this issue. Implication of resource reallocation is the erosion of a structured approach to mitigating risks.

Failure to manage one risk can very quickly escalate to a reactive management environment which is not only ineffective but potentially prohibitively resource intensive. Misallocation of resources could lead to risks manifesting which could have dire impacts on a company's share price as a function of its reputation.

\subsection{Suggested structure}

From the discussion presented, the following outline of a risk-informed tailings management structure is suggested:

1. Risks posed by TSFs should be understood in the context of other assets and their importance and influence to the business.

2. Inherent risk associated with a TSF or a portfolio of TSFs should be understood.

3. Key failure modes of the inherent risk should be defined and both regulatory and organisational controls for each of the modes should be understood. Controls may be physical or administrative, can apply to any phase of the TSF's life (planning, design, construction, operation, closure, post-closure) and should have a clearly defined performance criteria.

4. Likelihood and credible consequences (and their alignment) should be informed by the effectiveness of the controls highlighted in 3.

5. Where a control is found to be ineffective the root cause should be identified with subsequent rectification, prior to resorting to the addition of new controls.

6. Risk should be regularly reviewed based on control effectiveness and due to any changes to the TSF. 
The example included in this paper shows the pitfalls of the misapplication of tools that assist to quantify risk. This should not be interpreted as a recommendation to avoid the use of such tools. Rather, the authors caution that it is important to understand when quantification is appropriate and how it should be applied. Quantification of likelihood could play a significant part in the application of the structure described, but it likely would need to be incorporated from the original assessment of each asset and within the risk management framework for all of the owner's assets. Otherwise, the likelihood of different scenarios occurring may be inconsistently determined and provide misleading results. Quantification may also assist to more accurately define risk once the ability of the site to implement operational controls is understood (i.e. utilising past performance as an indicator of future performance).

\subsection{Application to historical failures}

An examination of historical failures suggests that the implementation of controls has had an impact on the rate of failure of TSFs. Oboni and Oboni (2016) examined historical failures from 1910 to 2009 and found that the implementation of peer review during design and regular inspections during operations reduced the PF by approximately an order of magnitude. Azam and Li (2010) report that there were nine historical failures due to overtopping between 1919 and 1999, but no failures due to overtopping in 2000 to 2009. Although the sample size is very limited and based on historical rates, only one failure would have been expected in the period of 2000 to 2009 . This change may be attributed to the implementation of operational controls for freeboard and emergency spillways, which have been common inclusions in regulations and industry guides in recent decades.

Historical failures also provide insights into the potential power of the implementation of a control framework. Consider, for example, the Merriespruit failure in South Africa in 1994. Several authors (Blight \& Fourie 2003; McPhail 2017) report that the supernatant pond was not in the intended location, an underdrain became inoperable over time and that the facility was ultimately operated with insufficient freeboard that meant a relatively minor rainfall event resulted in overtopping. As with the novel example provided, each of these issues could each have been addressed with a single robustly designed operational control. Each control may also provide some redundancy for other controls; for example having the pond in the intended location may have meant that the clogged underdrain may not have contributed to the consequences of the incident, as it may have assisted to limit the volume of tailings mobilised after a breach of the impounding embankment materialised.

\section{$4 \quad$ Concluding remarks}

Regulatory and industry guides focus on the inherent consequence (i.e. catastrophic failure of a TSF), as the default scenario for consequence assessments. On one hand, this approach is valid as it helps determine some of the minimum controls required to effectively manage the asset. On the other hand, however, this is problematic for a risk-based TSF management approach as it fails to recognise that an effective suite of controls can alter the credible consequence and likelihood for a period of time. This sensitivity could enable different types of management decisions without compromising the effectiveness of controls.

The three lines of defence model can readily support the shift to such an approach as it recognises that multiple parts of the business have a role to play in ensuring a robust management of TSFs. This integrated approach recognises that different areas have the corporate mandate and competence to implement critical controls. Clearly articulated control performance criteria both for design and implementation enable a simple and transparent identification of gaps in the controls framework that empowers management to make appropriate decisions even when they are not a subject matter expert. 


\section{References}

Arnauld, A \& Nicole, P 1996, Logic or the Art of Thinking, Cambridge University Press, Cambridge.

ANCOLD 2012, Guidelines on Tailings Dams - Planning, Design, Construction, Operation and Closure, Australian National Committee on Large Dams, Hobart.

Aven, T \& Renn, O 2009, 'On risk defined as an event where the outcome is uncertain', Journal of Risk Research, vol. 12, no. pp. 1-11.

Azam, S \& Li, Q 2010, 'Tailings dam failures: a review of the last one hundred years', Geotechnical News, vol. 28, pp. 50-53.

Blight, GE \& Fourie, AB 2003, A Review of Catastrophic Flow Failures of Deposits of Mine Waste and Municipal Refuse, introductory report of the International Workshop on Occurrence and Mechanisms of Flows in Natural Slopes and Earthfills, 14-16 May 2003, Sorrento.

Boshoff, J 2015, 'Responsible tailings management', Proceedings of the First Tailings and Mine Waste Management for the 21st Century Conference, The Australasian Institute of Mining and Metallurgy, Melbourne.

Bruce, IG \& Oboni, F 2002, 'Risk-management process for tailings control', Mining Engineering, vol. 54, no. 10, pp. $14-17$.

Christian, JT, Ladd, CC \& Baecher, GB 1994, 'Reliability applied to slope stability analysis', Journal of Geotechnical Engineering, vol. 120, no. 12, pp. 2180-2207.

Dai, SH \& Wang, MO 1992, Reliability Analysis in Engineering Applications, Van Nostrand Reinhold, New York.

Duncan, MJ, 2000, 'Factors of safety and reliability in geotechnical design', Journal of Geotechnical and Geoenvironmental Engineering, vol. 126, no. 4, pp. 307-316.

International Organization for Standardization 2018, ISO 31000:2018 Risk Management - Guidelines, International Organization for Standardization, Geneva.

Martin, TE \& Davies, MP 2002, Trends in the Stewardship of Tailings Dams, AGRA Earth \& Environmental Limited, Burnaby.

McPhail, GI 2017, 'Water management measures at TSFs and problems related to poor management', Management, Operation and Relinquishment of Tailings Storage Facilities Seminar, 29-30 April, Perth.

MAC 2017, A Guide to the Management of Tailings Facilities, 3rd edn, The Mining Association of Canada, Ottawa.

Murray, L, McLeod, H \& Suter, G 2010, 'Effectiveness in risk assessment - a comparison of perceived and realised risk from project concept to construction and operation', Proceedings of the First International Seminar on the Reduction of Risk in the Management of Tailings and Mine Waste, Australian Centre for Geomechanics, Perth, pp. 217-228.

Oboni, F \& Oboni, C 2016, A Systematic Look at Tailings Dams Failure Process, Riskope, Vancouver.

Payne v TIWEST Pty Ltd 2005, WASC 141.

PricewaterhouseCoopers 2012, 15th Annual Global CEO Survey 2012, PricewaterhouseCoopers, London, 40 p.

Sotic, A \&Rajic, R 2015, 'The review of the definition of risk', Online Journal of Applied Knowledge, vol.3, issue 3, pp. $17-26$.

The Institute of Internal Auditors 2013, IIA Position Paper: The Three Lines of Defense in Effective Risk Management and Control.

US Department of the Interior Bureau of Reclamation 2015, Best Practice in Dam and Levee Safety Risk Analysis, US Department of the Interior Bureau of Reclamation, Washington DC. 